\title{
El Periodismo como materia de enseñanza
}

Muchos periodistas, sobre todo en Europa, creen que el periodismo no se puede enseñar. Ninguno, claro está, cree que no se puede aprender. Creen, por lo tanto, que solo puede uno aprenderio por sí mismo. Si esto fuera cierto, sería una enseñanza, la del periodismo, original, exclusivamente autodidacta. Es verdad que el último acento del periodista, su personalidad, no.se la puede dar nadie. Pero, lo mismo ocurre en las actividades inteleduales Chás râcionalizadas.

Se enseñan las Jdencias fístçaseylilasonaturales; si no se enseña todavía a inventar, se enseña a adquirir las mejores condiciones para inventar... Y el tener inventiva no se enseña. El periodismo, además, si tiene algo de ciencia y no poco de arte, es, sobre todo, una profesión. Para el periodista. Para las empresas, es una industria. Para los gobiernos y los partidos, es un instrumento. Frente a los otros poderes del. pericdismo, el periodista ha de afirmar su carácter prefesional.

Por eso las escrieias de periodismo, por el solo hecho de existir, dignifican la profesión periodística. Esta es su primera consecuencia. $Y$ enseñan. ¿A qué? ¿A escribir? ¿A leer? ¿A ver? No se dan tales enseñanzas en otras escuelas, empezando a darla las primarias? ¿Cuál es la especialización del periodista? Las escuelas de periodismo tienen que responder, con su funcionamiento, a tales preguntas.

Es una paradoja verdadera que la especialización del periodista consiste precisamente en no tenerla. Parece una cosa fácil a primera vista eso de no tener ninguna especialidad. Piense el lector un poco y se percatará en seguida de lo difícil que es no tenerla en el mundo es- 
pecializado en que vivimos. ¿Quién no es hoy especialista en su trabajo? En la complicación de las actividades civilizadas, ¿a quién le es posible dedicarse a más que a la parte de un todo? Lo frecuente es que sea a la parte de una parte. En el mundo especializado se produce naturalmente una vida de tullidos, de fenómenos muy desarrollados en su especialidad y con las demás curiosidades atrofiadas, reducidas a muñones gesticulantes. Fuera de su especialidad, el hombre moderno no hace sino gestos.

Pero, como, incluso en la inteligencia, la naturaleza tiene horror al vacío, las curiosidades atrofiadas necesitan actuar de cualquier modo, como puedan. A un hombre de mucho saber que había pasado por la Escuela Normal Supericr de París, le oí decir que, en realidad, todo lo que sabía, lo había aprendido en los periódicos. Quitando lo que haya en esta frase de prurito elegante, ahtipedantesco, queda un gran fondo de verdad. Los hombres más aabios de nuestro tiempo, aparte de su especialidad, poco sabrían si no fuese porque hablan de ello los periódicos y las revistas de carácter generál, salvo en lo referente a la otra actividad compensadora, que el especialista sue'e tener. La existencia de tal actividad compensadora, comprueba que existe la necesidad de completar las curiosidades atrofiadas. El físico Einstein toca el violín, como hacía el pintor Ingres. Ios médicos están ya casi obligados a interesarse especialmente por la literatura o las bellas artes. El periodista considerado combespeciâlista tiene tambiens $s u$ violín: la co'ección más interesante đ̄ovaliose decpinturà rrodermasque había en París era la del periodista que inventó, en "Lo Matin", las noticias en tres líneas.

Ya se comprenderá, por lo que llevo dicho, cual es la especialización paradóicica del periodista, que consiste en no tenerla. El periodista es el especialista en dar vida a lás actividades muertas de los otros. Es la vestal encargada de mantener viva la llama en todos los conocimientos, en todos los órdenes, con sus últimas noticias. Cierto es que la vestal puede prostituirse. Puede rebajar su cometido y ser una comadre. "Eso, es periodismo", dicen los hombres de ciencia ante una divagación científica sin rigor. Llevan razón. "Eso, es periodismo", dicen los literatos ante un libro que cuenta cosas vulgarmente. También llevan razón. "Son cosas de los periódicos", dicen los políticos ante los rumores inciertos. Los políticos llevan menos razón, porque son ellos quienes originan o dan motivo a los rumores, pero, es verdad que los periódicos pueden amplificarlos o deformarlos. La "res", la cosa que en vez de ser la cosa pública, la república de las letras, de la.s cien- 
cias, de la sociedad, es las cosas, la cosa cualquiera, a eso se llama periodismo en el sentido peyorativo de la palabra.

En su sentido Iecto, periodismo es poner al alcance de todos la república de los hechos y las ideas del momento que cada cual por sí no podría alcanzar. El periódico es la enciclopedia al día. Pocos monumentos literarios más venerables que la colección secular de un gran periódico. Para dedicarse a tamaña tarea toda preparación parece poca. El periodista no puede ser enciclopédico. Dentro de su especialización que consiste en no tenerla, en sacar de sus casillas a los demás contándoles lo que ocurre, no solamente lo que pasa, en el mundo, presentando a éste con periodicidad, en cortes verticales, es decir cultivando especialmente la actualidad, el periodista tiene que especializarse a su vez. Cada día más. Sigue en esto la ley común a todos los especialistas. Se es periodista de una sección del periódico y no de todas. Tan necesarias son las escuelas de periodismo que, por muy dotadas que se piensen, resultan insuficientes. En ninguna se podrían enseñar todas las especializaciones indispensables para lográr cotidianamente el trabajo enciciopédico que supone hacer un gran diario.

Hay, sin embargo, un conocimiento nuclear de organización y de técnicas puramente periodísticas, que por sí solo justificaría la existencia de las escuelas de periodismo, pues, cada vez más también, exige un aprendizaje. Material, moral, intelectualmente, en todos sentidos, pocas cosas públicas sB han tomplicado tanto en un siglo como el perió-

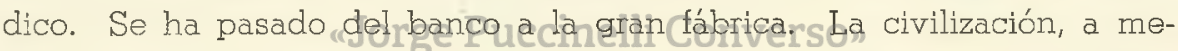
dida que ha ido especializando al hombre, ha ido perfeccionando y rnultiplicando los medios de mantenerle en comunidad. El periodismo, en el periódico escrito, en la rädio y en el cine, es la gran compensación humana de nuestro tiempo. Todavía no se ha estudiado todo lo que hay de periodismo en el cine y en la radio, además de los noticiarios cinematográficos y de los periódicos hablados. Lo que hay de periodismo en la música a domicilio y en la ventana que, sin moverse de una butaca, todo espectador aislado en la oscuridad del cine tiene abierta al mundo. Los ermitaños se instalaban antiguamente en el desierto. Los solitarios de hoy abundan en las ciudades de mayor población. Hojeando el periódico mientras se desayunan (a veces peor que los ermitaños con langostas, naturalmente, no de mar, de desierto), escuchando la radio mientras se ponen la corbata (suplicio parecido al del cilicio), recogiéndose por la noche en un ciné, que es el aislamiento, la ermita de todos, viven en soledad y en compañía, en comunicación con el universo, como los ermitaños antiguos mirando al cielo. 
Mirando al cielo se hicieron los primeros periódicos, los calendarios, cuando los hombres eran eternos y los astros la actualidad. Con esto reconozco la verdad evidente de que ha habido periodistas antes de haber escuelas de periodismo. También ha habido médicos antes que escuelas de medicina. Una cosa es la escuela de periodismo y otra la escuela de los periodistas. La escuela de periodismo ha de ser un centro de enseñanza; la escuela de los periodistas es el universo.

\section{Corpus Barga.}

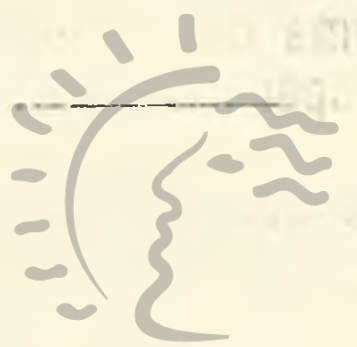

Biblioteca de Letras "Jorge Puccinelli Converso» 